\title{
Trajectory matching and dispersion modeling of volcanic plumes utilising space-based observations
}

\author{
Cordelia Maerker, Katrin \\ Seidenberger, Thilo Erbertseder \\ German Remote Sensing Data Center \\ German Aerospace Center (DLR) \\ Wessling, Germany \\ Cordelia.Maerker@dlr.de
}

\author{
Meike Rix, Pieter Valks \\ German Remote Sensing Data Center \\ German Aerospace Center (DLR) \\ Wessling, Germany
}

\author{
Jos van Geffen \\ Belgian Institute for Space Aeronomy \\ (BIRA-IASB) \\ Brussels, Belgium
}

\begin{abstract}
Within the projects SACS (Support to Aviation Control Service) and Exupéry (the mobile volcano fast response system, VFRS) $\mathrm{SO}_{2}$ total columns are retrieved from different space-borne instruments such as GOME-2, SCIAMACHY and OMI. The backward trajectory matching technique is applied to relate exceptional $\mathrm{SO}_{2}$ values to particular sources and volcanic regions. Additionally, the moment of the eruption as well as the emission and the plume height can be estimated. Dispersion modeling is applied to forecast the motion of the plume and to estimate the $\mathrm{SO}_{2}$ emissions.
\end{abstract}

Keywords-Exupéry VFRS; SACS; sulphur dioxide; trajectory matching; dispersion modeling

\section{INTRODUCTION}

Volcanic eruptions and unrest are among the main natural hazards, which influence nature, human beings and climate. During an eruption large amounts of solid matter and gases are emitted and the hazardous ash particles remain in the atmosphere for several days. The injection height depends on the kind of eruption and meteorological parameters such as the wind and humidity field and the stratification. $80 \%$ of the ash clouds of explosive eruptions reach more than $6 \mathrm{~km}, 60 \%$ more than $10 \mathrm{~km}$ and 20\% more than $15 \mathrm{~km}$ [1].

On average 10 plumes per year come up to flight levels. Since volcanic ash and trace gases may damage the material and engines of aircrafts, they also affect air traffic. As fine ash particles do not show up on radar and cannot be seen at night or in clouds an early warning service or at least a fast response system is a great support for aviation [2, 3]. Most of the active volcanoes are not monitored regularly yet. Satellite observations can aid to provide global information in near-real time. Some space-based instruments can directly detect volcanic ash, though this is still under development. Satellite instruments like GOME-2 (Global Ozone Monitoring Experiment) on Metop-A or OMI (Ozone Monitoring Instrument) on EOS-Aura are able to detect sulphur dioxide $\left(\mathrm{SO}_{2}\right)$, which is one of the volcanic gases that are emitted during a volcanic eruption or unrest. $\mathrm{SO}_{2}$ is a good marker for volcanic unrest and can help pinpoint emitted ash clouds. Moreover as $\mathrm{SO}_{2}$ can dissolve in water droplets and form to sulphuric acid, it is a hazard to aviation itself. The acid damages the surfaces of aircraft and sulphate components can deposit in engines [2].

The satellites are polar orbiting and reach a global coverage within about 1 day. Therefore it is sometimes difficult to relate an observed $\mathrm{SO}_{2}$ peak to a special volcano or a volcanic region. The main focus of this paper is the application of a robust trajectory analysis technique using ensembles and dispersion modeling to derive information about the source, origin and transport of sulfur dioxide and volcanic ash.

Trajectory models such as the HYSPLIT (Hybrid SingleParticle Lagrangian Integrated Trajectory) model of the National Oceanic and Atmospheric Administration (NOAA) have been applied for studying volcanic ash transport and dispersion. These models analyse and predict particle transport with single trajectories calculated for several heights [4]. Case studies of recent volcanic eruptions have been carried out using the enhanced trajectory matching technique that starts trajectory ensembles from a specified geolocation [5]. To estimate the vertical profile of volcanic $\mathrm{SO}_{2}$ emissions from satellite observations an analytical inversion method utilising an atmospheric transport model has been developed [6].

A combination of satellite observations, trajectory ensemble calculations and state-of-the-art dispersion modeling offers a profound analysis and forecast of volcanic $\mathrm{SO}_{2}$ transport with a high spatial and temporal resolution. Satellite data provide the location of enhanced volcanic $\mathrm{SO}_{2}$ values from which the trajectory ensembles can be started. The results are used as the first guess for the source term of the atmospheric transport model. The techniques are currently applied and refined in an operational environment within the Support to Aviation Control Service (SACS) [2] and Exupéry [3] and are tested for recent volcanic events such as the eruption of Mt. Etna (Italy) in May 2008 and Mt. Okmok (Alaska) in July 2008. They will be described in this paper on the basis of the eruption of Mt. Kasatochi (Alaska) on 07th August 2008.

\section{THE ERUPTION OF MT. KASATOCHI}

The Kasatochi volcano is a stratovolcano composed of basaltic and andesitic flows and pyroclastics. It is a $5 \mathrm{~km}^{2}$ island $\left(52.18^{\circ} \mathrm{N}, 175.51^{\circ} \mathrm{W}\right)$ that belongs to the Aleutian 
Islands of southwestern Alaska (USA) consisting of one single cone. The crater contains a saltwater lake with a diameter of about $0.8 \mathrm{~km}$.

After being inactive for more than 200 years the Kasatochi volcano erupted on 07th August 2008. An ash cloud spread out about $800 \mathrm{~km}$ in a counter clockwise spiral leading Alaska Airlines to cancel 44 flights between 10th and 11th August 2008. Apart from volcanic ash, the Kasatochi emitted large amounts of sulphur dioxide. Whereas the ash particles got deposited after a few days, the trace gas dispersed throughout the whole northern hemisphere. The atmospheric sensor GOME-2 delivered global near-real-time SO2 data showing the hemispheric transport of the SO2 plume and the formation of separate curls by the wind (Fig. 1). The plume arrived over Europe on 14th August 2008 and took 7 more days for reaching Alaska again.

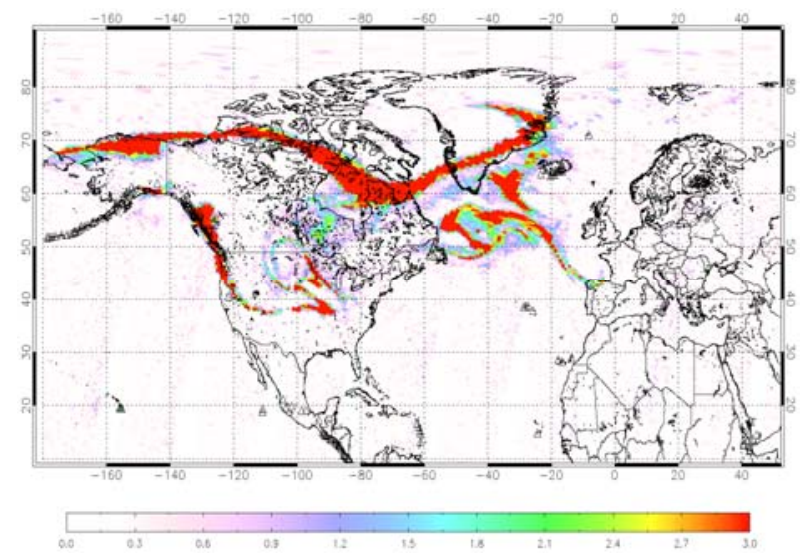

Figure 1. SO2 plume from Kasatochi eruption (07th August 2008) detected by GOME-2 on 14th August 2008.

The identification of the exact eruption time by eye witnesses was not possible since the crater was in clouds. One of the first signs of the eruption was an increased $\mathrm{SO}_{2}$ amount measured by OMI a few hours before the eruption.

\section{SATELLITE OBSERVATIONS}

The model calculations are initialised by observations of the GOME-2 instrument on the polar orbiting satellite MetopA. Total vertical $\mathrm{SO}_{2}$ columns are provided in near-real time within 2 to 3 hours after the measurement. They are offered globally within about 1 day at a spatial resolution of $80 \times 40$ $\mathrm{km}^{2}$.

The $\mathrm{SO}_{2}$ concentrations are retrieved from the solar backscatter measurements in the ultra-violet spectral range between 315 and $326 \mathrm{~nm}$ applying the well-established Differential Optical Absorption Spectroscopy (DOAS) approach [7]. Absorption cross sections for $\mathrm{SO}_{2}$ and the Ring effect correction are fitted simultaneously and the background corrections due to the interference between ozone and sulphur dioxide are disposed [5].

This method has been optimised for the GOME-2 instrument using an appropriate air mass factor (AMF), which is calculated by a radiative transfer model [8]. The AMF depends on the viewing geometry, the reflection characteristics of the underlying surface and the presence and optical properties of clouds and aerosols. For validation purposes the trajectory matching and the dispersion modeling results are used though the AMF depends also on volcanic plume height.

\section{TRAJECTORY ANALYSIS}

In order to attribute increased $\mathrm{SO}_{2}$ values as located in the satellite-based data to a volcanic or even anthropogenic source and to determine the plume und injection heights the trajectory matching technique is applied [9]. Therefore the state-of-the-art 3D kinematic trajectory model FLEXTRA is used. Input data are wind and temperature fields from the numerical weather prediction models of the European Center for Medium Range Weather Forecast (ECMWF) or the National Oceanic and Atmospheric Administration (NOAA). Ensembles of backward trajectories at different pressure levels from ground up to 20 $\mathrm{km}$ are released from the geolocation of an enhanced $\mathrm{SO}_{2}$ column observation. The starting point is not confined to the center coordinate of a pixel. It is rather defined as an air mass (e.g. a volume).

For the trajectory analysis two cases are distinguished. In the first case, if the volcanic source and the eruption time are known, the trajectories that pass the volcano's coordinates can be filtered in dependency of the heights and the time. It follows a distribution of the injection heights for the moment of the eruption. In the second case, if the emission source is unknown, the trajectories are counted for every grid cell. With that information a trajectory density map is delivered indicating the most probable source of an $\mathrm{SO}_{2}$ plume.

All this allows confirming the volcanic origin of the observed $\mathrm{SO}_{2}$ peak, determining the effective injection height and revealing the spatial and temporal evolution of the $\mathrm{SO}_{2}$ plume in near-real time after the satellite measurement. In order to reconfirm the estimated volcanic source and the appropriate emission height, ensembles of forward trajectories are released at the volcano for different levels between $0 \mathrm{~km}$ and $20 \mathrm{~km}$ above mean sea level. By matching these forward trajectories with the first-guess $\mathrm{SO}_{2}$ retrieval of GOME-2 the backward trajectory results can be verified. In addition the HYSPLIT model of NOAA and the Lagrangian particle dispersion model FLEXPART are applied for validation tasks.

\section{DISPERSION MODELING}

As trajectory models deliver rather qualitative information and neglect processes like convection and turbulence, the more exacting Lagrangian particle dispersion model FLEXPART is utilised for the further analysis of the satellite observations [10]. FLEXPART has been disposed in many studies of the long-range atmospheric transport even of volcanic ash [11]. It was validated on the basis of continental-scale tracer experiment data [12].

The calculations are based on meteorological fields of numerical weather prediction models (ECMWF, GFS, MM5) and provide a three dimensional forecast of the transport of volcanic ash and $\mathrm{SO}_{2}$ plumes. The meteorological parameters 
of the ECMWF model with a spatial resolution of $1^{\circ} \mathrm{x} 1^{\circ}$ and a temporal resolution of 3 hours at 91 vertical levels were used to study the Kasatochi eruption in August 2008.

The trajectories of the air parcels are calculated by interpolation of the ECMWF wind fields and random movements that represent turbulence. Although the removal processes of $\mathrm{SO}_{2}$ are important for a comparison with spacebased data several days after an eruption, it has been neglected in the first case studies.

The start and end times of the eruptions as well as the injection heights were taken from the trajectory model results as a first guess. By comparison between the model results and the satellite-based measurements the source terms have been adjusted. On a $0.5 \times 0.5^{\circ}$ output grid the 17 days following the first Kasatochi eruption were simulated. The concentrations were calculated for 16 vertical layers reaching from $5000 \mathrm{~km}$ to $20000 \mathrm{~km}$ with a vertical resolution of $1 \mathrm{~km}$. For comparison purposes with the satellite data the total vertical columns were calculated.

\section{RESUlTS}

This section presents the results of the trajectory analysis and the dispersion modeling for the selected eruption of Mt. Kasatochi in August 2008. Input data for the trajectory ensembles were GOME-2 $\mathrm{SO}_{2}$ observations. The calculated emission heights and dates were the first guess for the dispersion modeling source term.

\section{A. Results of the trajectory analysis}

The vertical column densities of $\mathrm{SO}_{2}$ as retrieved from GOME-2 on 08th August 2008 are shown in Figure 2. The enhanced values over the Aleutian Islands were the first hint for this eruptive period and hence the geolocations of the 7 maximum data were used to start the trajectory ensembles.

The analysis revealed a most probable volcanic source as shown in the trajectory density map in Figure 3. The southern Aleutian Islands are marked as the emission region. One of the most probable volcanoes is Mt. Kasatochi.

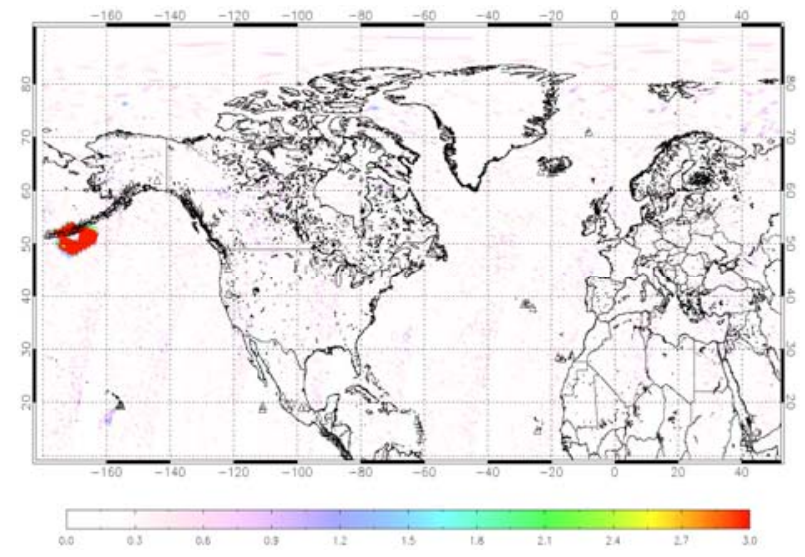

Figure 2. SO2 plume from the Kasatochi eruption (07th August 2008) detected by GOME-2 on 08th August 2008.
The relation between the enhanced GOME-2 $\mathrm{SO}_{2}$ values and Mt. Kasatochi is displayed in Figure 4. A small cyclone transported the particles in a circular motion. The backward trajectories are filtered in respect of passing the Kasatochi volcano. This results in a distribution of the most probable emission heights as seen in Figure 5. It shows an injection height between 8 and $14 \mathrm{~km}$ with a maximal probability at 12 $\mathrm{km}$.

In order to reconfirm the emission source as well as the appropriate height, forward trajectory ensembles were started at the coordinates of Mt. Kasatochi on 08th August 2008 at 04 UTC. The simulations extended over the five following days and the trajectories are filtered for selected satellite-based $\mathrm{SO}_{2}$ measurements. Figure 6 shows the result which revealed an emission height of about $10 \mathrm{~km}$ for the selected $\mathrm{SO}_{2}$ pixel.
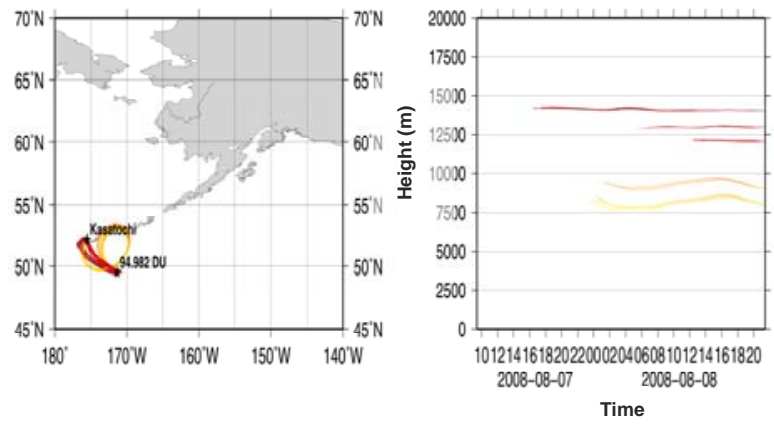

$0 \quad 1500 \quad 3000 \quad 45006000750090001050012000135002000050000$

Figure 3. Backward trajectories starting on 08th August 2008. Subset related to Mt. Kasatochi and GOME-2 $\mathrm{SO}_{2}$ data.

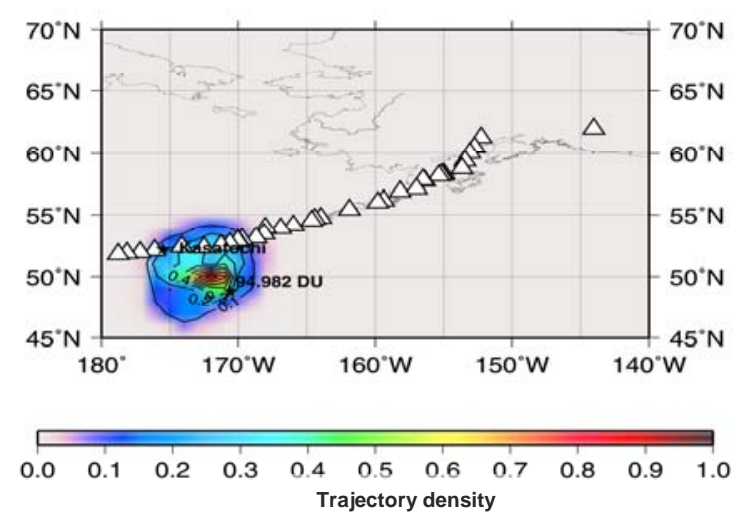

Figure 4. Trajectory density map indicating probable sources of the enhanced $\mathrm{SO}_{2}$ values measured by GOME-2 on 08th August 2008. 


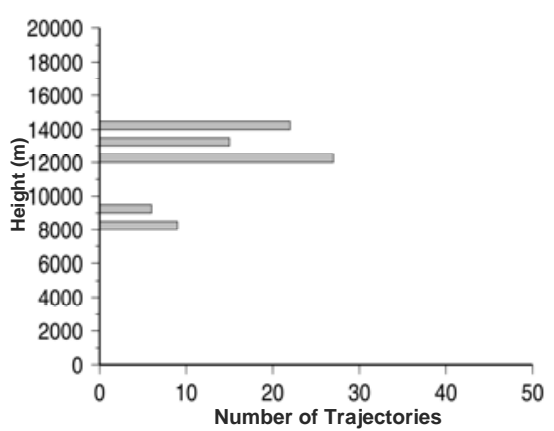

Figure 5. Estimated emission height of the Kasatochi eruption (7th August 2008)
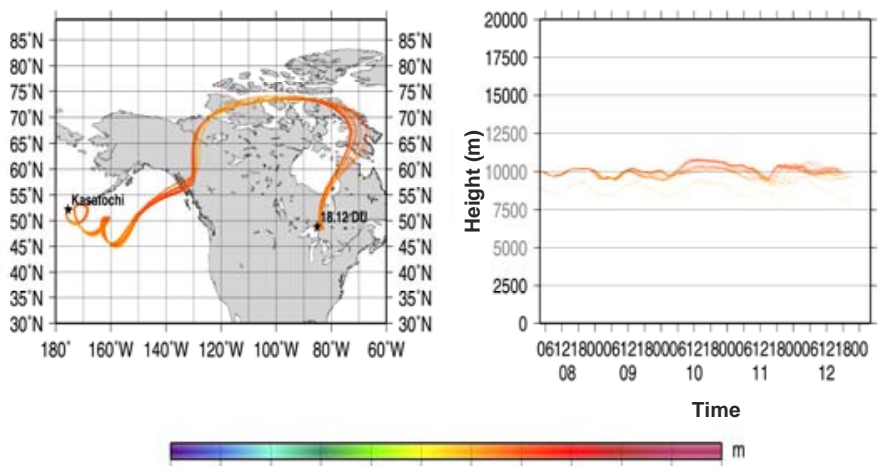

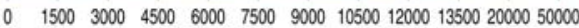

Figure 6. Forward trajectories starting on 08th August 2008 at 04 UTC. Subset related to Mt. Kasatochi and GOME-2 $\mathrm{SO}_{2}$ data.

A comparison with the measurements of GOME-2 on 13th August 2008 offers a good agreement in the dispersion and transport of the $\mathrm{SO}_{2}$.

\section{B. Results of the dispersion modeling}

The results of the trajectory analysis were used as the source term for FLEXPART at a first guess.
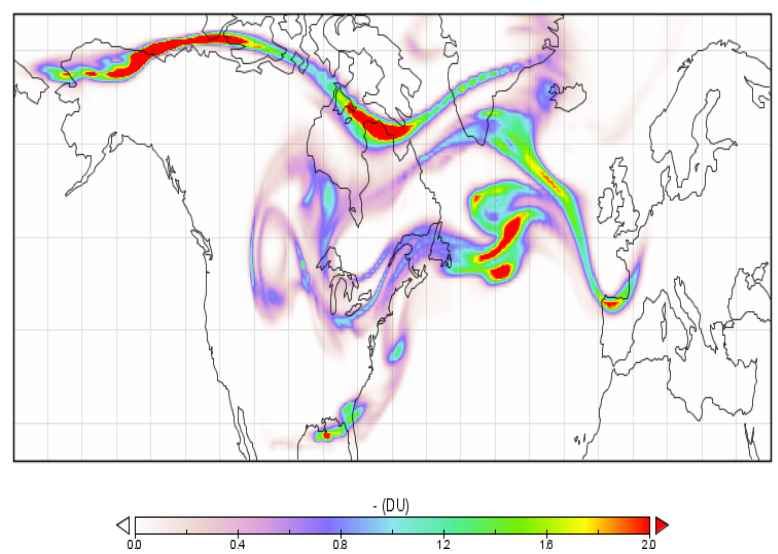

Figure 7. Modeled $\mathrm{SO}_{2}$ plume of the Kasatochion eruption on 14th August 2008 at 18 UTC.
By a comparison with the GOME-2 measurements 2 emission moments could be determined. The first started on 07th August 2008 at 21 UTC and ended on 08th August 2008 at 4 UTC. The $\mathrm{SO}_{2}$ emission level was between 10 and $12 \mathrm{~km}$. Within this layer a tracer of $1.5 \mathrm{E}+7 \mathrm{~kg}$ carried by 500000 particles was released from a point source representing the volcano. The second emission started on 08th August 2008 at 4 UTC and ended at 7 UTC. The injection height was the same as for the first emission. However, the mass of $1.5 \mathrm{E}+7 \mathrm{~kg}$ was carried by 400000 particles.

Figure 7 presents the modeled $\mathrm{SO}_{2}$ plume on 14th August 2008, 7 days after the eruption. It agrees well with the satellitebased observations in Figure 1 (please note the different projections). Minor changes result from the sensitivity of the GOME-2 instrument, the occurrence of clouds and the estimated source-term (total mass, total number of emitted particles, etc.) for FLEXPART. Attention should also be paid to the different time scales of the model and the satellite. While the model results show a snapshot of the dispersed $\mathrm{SO}_{2}$ tracer, the GOME-2 observation is a composite of data collected for various moments of one single day.

\section{CONCLUSION}

With the aid of state-of-the-art 3D trajectory models the GOME-2 $\mathrm{SO}_{2}$ observations can be interpreted regarding the estimation of the emission source, time and height. It is possible to determine a volcanic region or at ideal case even a single volcano as an emission source. Several case studies were carried out, i.e. for the eruptions of Mt. Etna (Italy) in May 2008, Mt. Okmok (Alaska) in July 2008 and Mt. Kasatochi (Alaska) in August 2008. Also the degassing of the Kilauea volcano on Hawaii observed by GOME-2 was investigated.

Volcanic eruptions are one of the main hazards to aviation. To decrease the risk of flying through an ash cloud an exact forecast in case of an eruption is essential. By combining the satellite-based $\mathrm{SO}_{2}$ retrieval with trajectory analysis and three dimensional atmospheric transport models the dispersion of $\mathrm{SO}_{2}$ or ash particles can be predicted with a high spatial and temporal resolution.

The International Civil Aviation Organisation (ICAO) has established the Volcanic Ash Advisory Centres (VAAC) to gather information on volcanic activity and to alert aviation in case of a possible danger. The Support to Aviation Control Service (SACS) of the project PROMOTE provides near-real time $\mathrm{SO}_{2}$ data from several satellite-based instruments and delivers notifications of enhanced $\mathrm{SO}_{2}$ concentrations. The $\mathrm{SO}_{2}$ data can be accessed via http://sacs.aeronomie.be/. Exupéry, a BMBF (German Federal Ministry of Education and Research) funded project within the GEOTECHNOLOGIEN programme on early warning systems for natural hazards, intends to assist the VAACs by developing a mobile volcanic fast response system (VFRS). The VFRS can be deployed quickly in case of volcanic unrest und combines ground-based and satellite-based measurements (http://www.exupery-vfrs.de/). The access to the GOME-2 $\mathrm{SO}_{2}$ data in the framework of Exupéry is provided via the World Data Center for Remote Sensing of the 
Atmosphere (WDC-RSAT) under the following link: http://wdc.dlr.de/data_products/SERVICES/GOME2NRT/so2.php.

\section{ACKNOWLEDGMENT}

We thank BMBF for funding Exupéry and ESA for funding PROMOTE.

\section{REFERENCES}

[1] M. M. Halmer and H.-U. Schmincke, "The impact of moderate-scale explosive eruptions on stratospheric gas injections,” in Bull. Volcanol., vol. 65, 2003, pp. 433-440.

[2] J. van Geffen, M. Van Roozendael, W. Di Nicolantonio, L. Tampellini, P. Valks, T. Erbertseder and R. van der A, "Monitoring of volcanic activity from satellite as part of GSE PROMOTE," Proceedings of the ENVISAT Symposium, Montreux, ESA publication SP-636, 2007.

[3] M. Hort and K. Zakšek, "Exupéry: the Mobile Volcano Fast Response System,” IEEE proceedings of 2nd USEReST workshop, Naples, 2008.

[4] B. J. B. Stunder., J. L. Heffter and R.R. Draxler, "Airborne Volcanic Ash Forecast Area Reliability,” in Wea. Forecasting, vol. 22, 2007, pp. 1132-1139.

[5] D. Loyola, J. van Geffen, P. Valks, T. Erbertseder, M. van Roozendael, W. Thomas, W. Zimmer and K. Wißkirchen, "Satellite-based detection of volcanic sulphur dioxidefrom recent eruptions in Central an South America,” in Adv. Geosci., vol. 14, 2008, pp. 35-40.
[6] S. Eckhardt, A. J. Prata, P. Seibert, K. Stebel and A. Stohl, "Estimation of the vertical profile of sulfur dioxide injection into the atmosphere by a volcanic eruption using satellite columns measurements and inverse transport modeling,” in Atmos. Chem. Phys. Discuss., vol. 8, 2008, pp. 3761-3805.

[7] U. Platt, "Differential optical absorption spectroscopy (DOAS)," in Air Monitoring by Spectroscopic Techniques, Chemical Analysis Series, vol. 127, M. W. Siegrist, Ed. New York: John Wiley \& Sons, Inc., 1994, pp. 27-84.

[8] M. Rix, P.Valks, N. Hao, T. Erbertseder and J. van Geffen, "Monitoring of volcanic SO2 emissions using the GOME-2 satellite instrument," IEEE proceedings of 2nd USEReST workshop, Naples, 2008.

[9] W. Thomas, T. Erbertseder, T. Ruppert, M. van Roozendael, J. Verdebout, C. Meleti, D. Balis and C. Zerefos, "On the retrieval of Volcanic Sulfur Dioxide Emissions from GOME backscatter measurements,” in J. Atmos. Chem., vol. 50, 2005, pp. 295-320.

[10] A. Stohl, C. Foster, A. Frank, P. Seibert and G. Wotawa, “Technical note: The Lagrangian particle dispersion model FLEXPART version 6.2,” in Atmos. Chem. Phys., vol. 5, 2005, pp. 2461-2474.

[11] A. J. Prata, S. A. Carn, A. Stohl and J. Kerkmann, "Long range transport and fate of a stratospheric volcanic cloud from Soufriere Hills volcano, Montserrat,” in Atmos. Chem. Phys., vol. 7, 2007, pp. 5093-5103.

[12] A. Stohl, M. Hittenberger and G. Wotawa, "Validation of the Lagrangian particle dispersion model FLEXPART against large scale tracer experiment data,” in Atmos. Environ., vol. 32, 1998, pp. 42454264. 